А.Л. ТИХОМИРОВ, Д.М.Н., професСор, В.В. КАЗЕНАШЕВ, К.М.Н., Т.А. ЮДИНА

Московский государственный медико-стоматологический университет им. А.И. Евдокимова

\title{
COBPEMEHНAЯ
}

\section{НЕГОРМОНАЛЬНАЯ КОРРЕКЦИЯ}

\section{МЕНОПАУЗАЛЬНЫХ НАРУШЕНИЙ}

\begin{abstract}
В обзорной статье представлена возможность использования биологически активных добавок к пище в лечении менопаузальных нарушений как альтернативы менопаузальной гормональной терапии. Комплексные препараты фитоэстрогенов, витаминов и аминокислот обладают широким протективным диапазоном в пери- и постменопаузальном периодах. Отмечена хорошая переносимость препаратов.
\end{abstract}

Ключевые слова: перименопауза, постменопауза, механизм действия фитоэстрогенов, биологически активные добавки к пище, препарат Менсе, эффективность, безопасность.

\section{A.L. TIKHOMIROV, MD, Prof., V.V. KAZENASHEV, PhD in medicine, T.A. YUDINA Evdokimov Moscow State Medical and Stomatologic University CONTEMPORARY NONHORMONAL CORRECTION OF THE MENOPAUSAL DISTURBANCES}

In the review paper is occurred the possibility of using the food supplements in the treatment of menopausal disturbances as the alternatives of menopausal hormonal therapy. The complex preparations of phytoestrogens, vitamins and amino acids possess broad protective band in the peri- and postmenopausal periods. A good transference of preparations is noted.

Keywords: Perimenopause, postmenopause, the mechanism of the action of phytoestrogens, dietary supplements, food supplements, preparation Mense, effectiveness, safety.

зменение демографической структуры общества в XXI в. привело к увеличению в популяции доли женщин старшей возрастной группы. По данным Всемирной организации здравоохранения (BO3), их количество к 2030 г. достигнет 1,2 млрд человек. Перименопауза и постменопауза, не являясь собственно заболеваниями, приводят к нарушению эндокринного равновесия в организме женщины, вызывая приливы, раздражительность, бессонницу, а в последующем - возможные урогенитальные расстройства, повышение риска развития остеопороза и сердечно-сосудистых заболеваний. Все эти данные свидетельствуют о необходимости разработки целого ряда медицинских и социальных мер по защите здоровья, сохранению работоспособности и достойного качества жизни женщин пери- и постменопаузального периода.

Менопаузальная гормональная терапия (МГТ) с использованием эстрогенов считается испытанным способом смягчения климактерических симптомов. Она улучшает самочувствие, общее состояние здоровья и качество жизни женщин. Однако длительное воздействие эстрогенов на организм повышает риск развития гиперплазии тканей-мишеней (эндометрия, молочных желёз). Успехи последних десятилетий в области фармаконутрициологии, возникшей на стыке диетологии, фармакологии и классической фитотерапии, нашли свое отражение и в гинекологии - в наибольшей степени при коррекции менопаузальных нарушений. Таким образом, МГТ в настоящее время уже не рассматривается как единственный и самодостаточный способ решения этой проблемы.
Толчком к внедрению новых биопрепаратов (БАД к пище) в гинекологию послужили результаты проведенных в 80-90-е гг. прошлого века эпидемиологических популяционных исследований, показавших, что у женщин в странах Юго-Восточной Азии наблюдается более позднее начало менопаузы и меньшая выраженность климактерического синдрома $(\mathrm{KC})$ по сравнению с европейками.

\section{Когда эндогенных эстрогенов становится настолько мало, что их не хватает для поддержания физиологического уровня стимуляции, даже относительно слабый стимулирующий эффект фитоэстрогенов может оказаться вполне достаточным, чтобы сгладить эстрогеновый дефицит}

Более того, у женщин в данном регионе уровень заболеваемости раком молочной железы, а также злокачественными новообразованиями матки и яичников примерно в 5 раз ниже, чем в странах Европы [1]. Объяснение этого феномена исследователи находят в традиционной диете жителей Юго-Восточной Азии с высоким уровнем потребления продуктов из сои, богатой такими фитонутриентами, как фитоэстрогены (ФЭ). Именно на ФЭ сегодня акцентируется внимание ученых всего мира, когда заходит речь об альтернативных подходах к коррекции менопаузальных нарушений. Как показали исследования, это действительно оправданно, поскольку данный класс соединений обладает широчайшим спектром фармакологи- 
ческой активности. Соединения, обладающие ФЭ-активностью, обнаружены примерно в 300 растениях, из которых далеко не все используются в пищу человеком или животными. Всего описано более 150 соединений этой группы. Физиологическое значение ФЭ для самих растений заключается в регуляции процессов роста и размножения, защите растений от агрессивного воздействия ультрафиолетового излучения, поражения грибами и другими паразитами, контроле действия других биологически активных соединений. Ряд этих соединений обладает антивирусными, антибактериальными и другими ярко выраженными биологическими эффектами [2]. Изофлавоноиды (ИФ) представляют собой производные гликозидов и в значительных количествах содержатся в различных частях практически всех бобовых растений. В кишечнике ИФ подвергаются комбинированному (ферментативному и бактериальному) гидролизу и дальнейшему метаболизму, в результате чего образуются соединения с эстрогенной активностью: формононетин, дайдзеин, генистеин, биоханин-А (рис. 1).

\section{Рисунок 1. Метаболизм изофлавоноидов (схема)}

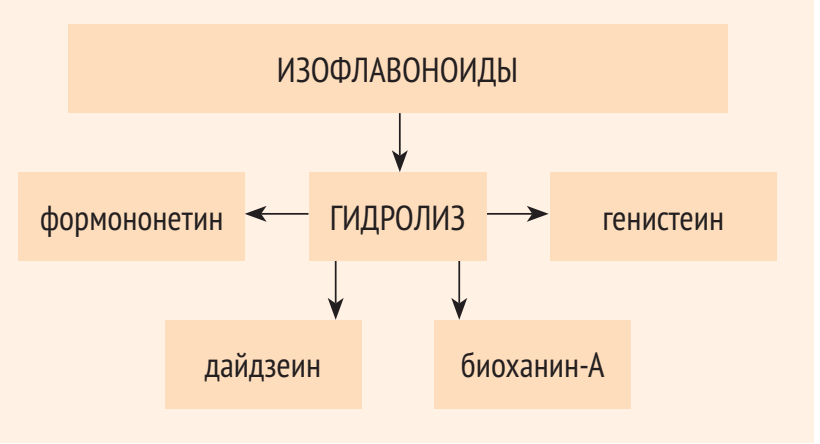

Исследования показали, что ФЭ обладают структурным сходством с эндогенными эстрогенами людей и животных и имеют близкую к ним молекулярную массу (рuc. 2).

Указанные свойства позволяют им «узнавать» эстрогеновые рецепторы и связываться с ними. Однако ФЭ априори обладают меньшей биологической активностью, поскольку характер их действия зависит не только от их способности быть подходящим «ключом» к «замку»рецептору, но и от способности «ключа» «открывать замок», т. е. стимулировать в клетке специфический синтез. В последнем случае ФЭ проявляют эстрогенные свойства. При отсутствии такой способности ФЭ, блокируя, но не стимулируя рецептор, могут выступать в качестве антиэстрогеновых агентов.

По сути, это означает, что ФЭ могут работать как избирательные модуляторы рецепторов эстрогенов (selective estrogen receptor modulators, SERMs), проявляющие в различных тканях эффекты агонистов (синергистов) либо антагонистов эстрогенов. Вдобавок к этому различные органы-мишени могут по-разному отвечать на стимулы эстрогенов и ФЭ в зависимости от соотноше-

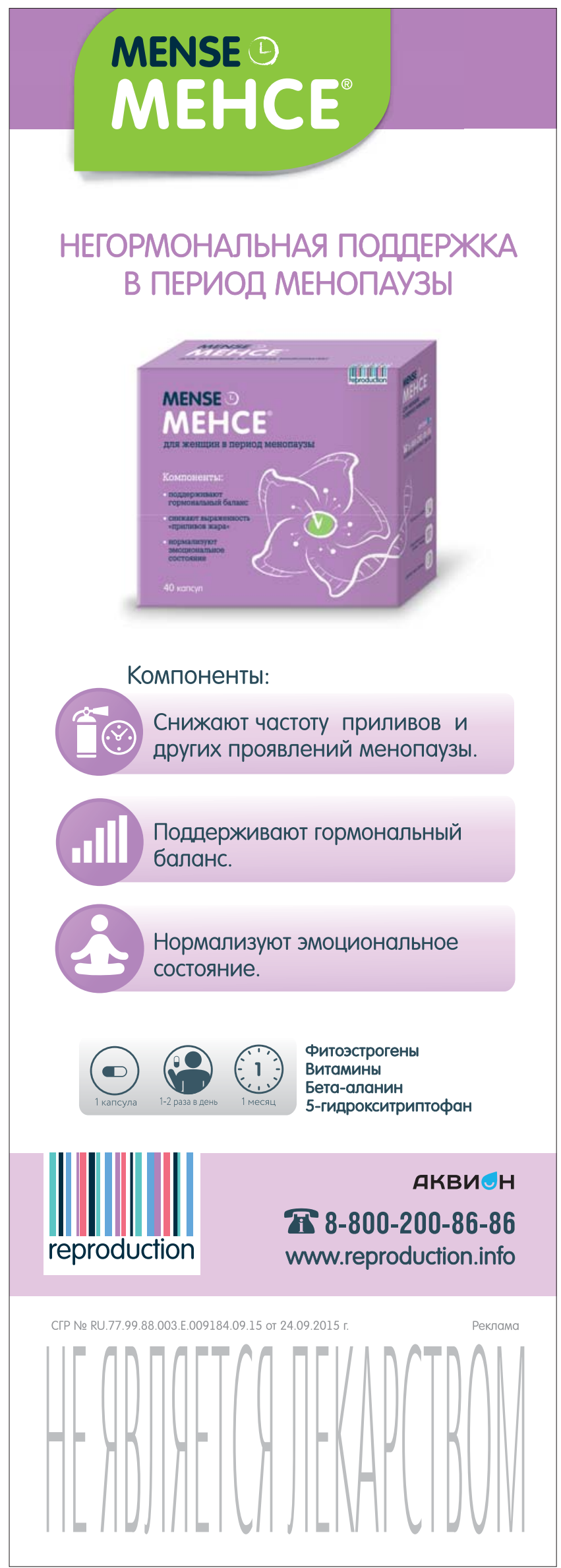




\section{Рисунок 2. Химическая структура Е2 и метаболитов изофлавоноидов}
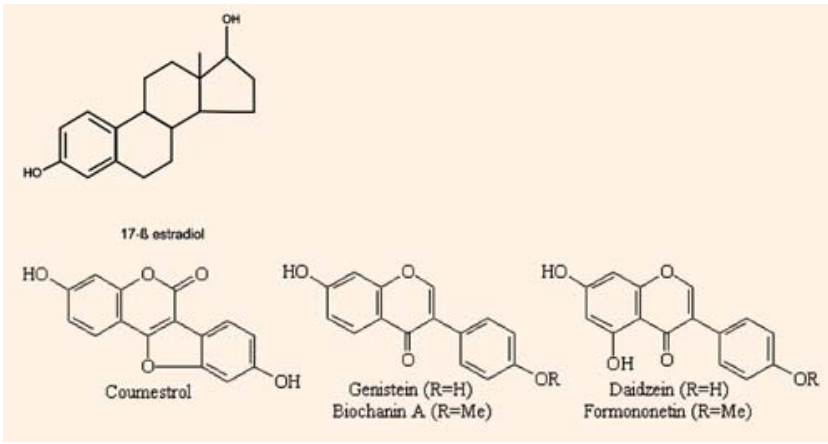

ния и распределения рецепторов (а и $\beta$ ) в них. В общем и целом ФЭ имеют более выраженную специфичность по отношению к $\beta$, нежели а-рецепторам. Однако более важным является то, что ФЭ и эндогенные эстрогены взаимодействуют с обоими типами эстрогеновых рецепторов по конкурентному принципу. При этом биологическая активность ФЭ (аффинитет и стимулирующий потенциал) существенно ниже, чем у естественных эстрогенов: по одним данным, в 1 000-10 000 раз, по другим - только в 20 раз [3-5]. По этой причине при нормальном или высоком уровне эндогенных эстрогенов ФЭ могут оказывать антиэстрогенное действие только при условии их высокой концентрации, достаточной для вытеснения эндогенных эстрогенов. Когда же эндогенных эстрогенов становится настолько мало, что их не хватает для поддержания физиологического уровня стимуляции, даже относительно слабый стимулирующий эффект ФЭ может оказаться вполне достаточным, чтобы сгладить эстрогеновый дефицит.

Очень важным, но менее известным является тот факт, что ФЭ оказывают регулирующее влияние на гормональный статус не только через стероидные рецепторы, но и другие гормон-опосредованные механизмы. Например, улучшают соотношение гидроксилированных метаболитов эстрогенов - снижают образование генотоксичных (канцерогенных) 16-ОН-эстрона и 4-ОН-эстрона и стимулируют образование более физиологичного 2-ОН-эстрона [6,7]. ФЭ стимулируют выработку ГСПГ в печени [8], тем самым снижая уровень свободных фракций эстрогенов в крови. Они также ингибируют активность ароматазы, уменьшая преобразование тестостерона и андростенедиона в эстрогены в жировой ткани и клетках молочных желез [7, 9, 10]. Bсе эти механизмы могут иметь большое значение для профилактики эстрогензависимых заболеваний.

Более этого, биологическая активность ФЭ значительно шире, чем только модуляция гормонального статуса. Так, например, как и все растительные фенолы, ФЭ проявляют выраженный антиоксидантный эффект, оказывают гиполипидемическое и антиатерогенное действие. Все больше появляется информации о наличии у ФЭ существенного антиканцерогенного потенциала, который связывают с антиоксидантными свойствами, способностью ингибировать активность ряда ферментов (протеинкиназ, ароматазы), влиянием на детоксикацию как эндогенных эстрогенов, так и ксенобиотиков, процессы дифференцировки клеток и неоангиогенеза.

Говоря об эффективности ФЭ, следует учитывать один важный нюанс - эффективность многих ФЭ обусловлена в основном не самими соединениями, а более активными их метаболитами, которые образуются при обязательном участии нормофлоры кишечника. Это следует обязательно учитывать при использовании ФЭ, поскольку дисбиотические изменения в кишечнике могут свести на нет все усилия врача и пациента.

Эффективность МГТ в коррекции основных симптоматических и асимптоматических проявлений КС не вызывает сомнений, так же как не вызывают сомнений риски, ассоциирующиеся с использованием МГТ. Учитывая это, многими исследователями все чаще и более смело высказывается идея о том, что ФЭ во многих случаях могут стать пусть и не полноценной, но вполне приемлемой альтернативой МГТ, исходя из соотношения эффективность/безопасность [11, 12]. И действительно, отсутствие негативных эффектов ФЭ по отношению к эндокринной системе женщин в разных периодах жизни было продемонстрировано в многочисленных исследованиях. Доказано, что прием ИФ в дозах около 50 мг в день в срок до 6 месяцев и более не оказывает влияния на такие показатели, как пролиферативная активность ткани молочной железы, толщина эндометрия, уровень ФСГ крови, изменения со стороны слизистой влагалища [13]. В целом, анализируя результаты серьезных исследований, а также данные ряда крупных зарубежных обзоров, можно сделать вывод, что ФЭ снижают частоту приливов в среднем на 40-54\% [14]. Безусловно, данный показатель несопоставим с результатами от применения МГТ - 80-95\%, но с учетом многочисленных недостатков МГТ ФЭ даже при таких цифрах смотрятся весьма выигрышно. К тому же, как показывает наш опыт, комбинация ФЭ с рядом других нутриентов (витамины группы В, аминокислотные прекурсоры нейромедиаторов и др.) может дать в совокупности очень высокий эффект, при этом не только в отношении вегетативной симптоматики.

\section{Внимание к достижениям и успехам фармаконутрициологии должно стать правилом хорошего профессионального тона для каждого прогрессивно мыслящего специалиста}

Множество нутритивных факторов могут влиять на синтез эстрогенов и активность их рецепторов, так же как и на пути их детоксикации. Дополнительное использование определенных нутриентов в составе БАД могут благотворно влиять на баланс эстрогенов, тем самым предотвращая развитие эстрогензависимых состояний и заболеваний в перименопаузальном периоде. Витамины группы В и фолиевая кислота действуют в качестве важных кофакторов для ферментов, участвующих в конъюгировании и метилировании эстрогенов. Поэтому дефицит витаминов группы В может нарушать детоксикацию 
эстрогенов и приводить к повышению уровня их вредных метаболитов [15-17]. Фолиевая кислота - необходимый кофактор метилирования катехолэстрогенов, которое уменьшает их превращение в канцерогенные квиноны [16]. Наиболее хорошо изученные и популярные нутриенты-антиоксиданты: витамины Е и С работают преимущественно как ловушки свободных радикалов. Аминокислотный прекурсор нейромедиаторов бета-аланин оказывает воздействие на терморегуляторное ядро гипоталамуса путем связывания с глициновыми рецепторами и с H3-рецепторами к гистамину, обеспечивая «быстрый эффект» в купировании вегето-сосудистой реакции в виде прилива. Метаболизация бета-аланина в ЖКТ с последующим накоплением карнозина и пантотеновой кислоты в организме стабилизирует энергетический метаболизм, снижая вероятность приливов и оказывая долговременный защитный эффект. При этом бета-аланин противодействует резкому высвобождению гистамина и брадикинина из тучных клеток и оказывает прямое стабилизирующее действие на мембраны тучных клеток, блокируя быстрое расширение сосудов кожи и покраснение. Не воздействуя на Н1-гистаминовые-рецепторы, бета-аланин не обладает побочными эффектами Н1-гистаминоблокаторов (сухость во рту, сонливость и т. д.). Другая аминокислота, 5-гидрокситриптофан, входящая в состав белков, в чистом виде в природе встречается, в частности, в семенах Griffonia simplicifolia. Является прекурсором нейротрансмиттера серотонина, в виде биологически активной добавки нередко используется как антидепрессант, супрессант аппетита и как вещество, помогающее бороться с бессонницей.

Безусловно, БАД пока имеют более слабую доказательную базу по сравнению с лекарственными препаратами, и, как любое относительно новое направление, нутрициоло- гия продвигается не без труда, но эта ситуация меняется буквально на глазах. Внимание к достижениям и успехам фармаконутрициологии должно стать правилом хорошего профессионального тона для каждого прогрессивно мыслящего специалиста. В свете выше сказанного значительный интерес для негормональной коррекции ряда менопаузальных нарушений представляет препарат МЕНСЕ комплекс изофлавонов сои и бета-аланина, усиленный 5-гидрокситриптофаном и витаминами. Компоненты МЕНСЕ купируют и предупреждают основные нейровегетативные и психоэмоциональные проявления КС, в т. ч. приливы жара $[18,19]$, нарушения сна и раздражительность [20]. Препарат назначается 1-2 раза в день, начинает действовать в течение 30 минут после приема [18].

Нарастающая популярность нутрициологического подхода, как, впрочем, и других альтернативных методов, обусловлена в первую очередь теми возможностями, которыми обычно обделены лекарственные препараты МГ: большая безопасность и широта терапевтической активности. Как бы рьяно ни противились ортодоксы медицины, широкое внедрение БАД к пище в повседневную клиническую практику происходит подобно «тихой революции» и игнорировать данные тенденции как минимум невежественно.

Во всяком случае, жительницы стран Западной Европы, США и Японии, у которых и выбор, и возможности значительно больше, чем у наших соотечественниц, все чаще прибегают к средствам и методам т. н. комплементарной и альтернативной медицины (complementary and alternative medications, CAM). Понятие САМ официально используется ВОЗ, включает «обширный комплекс средств фармакологического воздействия, убеждений, технологий и упражнений» и применительно к менопаузе предназначено не только для уменьшения тяжести ее проявлений, но и для улучшения качества жизни.

\section{ЛИТЕРАТУРА}

1. Nagata C, Takatsuka N, Kawakami N, Shimizu H. Association of diet with the onset of menopause in Japanese women. Am. J. Epidemiol., 2000, 152(9): 863-867.

2. Дерфлинг К. Гормоны растений. Системный подход. М.: Мир, 1985, 303 с. / Derfling K. Herbal hormones. Systemic approach. M: Mir, 1985, 303 p.

3. Капрельянц Л.В., Киселев СВ., Иоргачева Е.Г. Изофлавоны сои и перспективы их терапевтического применения Вопросы питания, 2003, 4: 36-41. / Kaprelyantz L.V., Kiselev S.V., Iorgacheva E.G. Soya isoflavones and prospects of their therapeutic application. Nutritional Issues, 2003, 4: 36-41.

4. Тутельян В.А., Павлючкова М.С, Погожева А.В. Применение фитоэстрогенов в медицине. Вопросы питания, 2003, 2: 48-54. / Tutelyan V.A., Pavlyuchkova M.S., Pogozheva A.V. Phytoestrogens applications in medicine. Nutritional Issues, 2003, 2: 48-54.

5. Morito K, Hirose T, Kinjo J, Hirakawa T. Interaction of phytoestrogens with estrogen receptors alpha and beta. Biol Pharm Bull, 2001, 24(4): 351-356.

6. Adlercreutz H. Hockerstedt K, Xu X, Duncan AM, Merz BE, et al. Effect of soy isoflavones on estrogen and phytoestrogen metabolism in premenopausal women. Cancer Epidemiol Biomarkers Prev, 1998, 7(12): 1101-08.

7. Xu X, Duncan AM, Wangen KE et al. Soy consumption alters endogenous estrogen metabo- lism in postmenopausal women. Cancer Epidemiol Biomarkers Prev, 2000, 9(8): 781-86.

8. Bannwart $\mathrm{C}$ et al. Effect of dietary components, including lignans and phytoestrogens, on enterohepatic circulation and liver metabolites of estrogens and in sex hormones binding globulin (SHBP). J Steroid Biochem, 1987, 27(4-6): 1135-44

9. Wang C, Makela T, Hase T et al. Lignans and flavonoids inhibit aromatase enzyme in human preadipocytes. J Steroid Biochem Molec Biol, 1994, 50: 205-12.

10. Adlercreutz H, Bannwart C, Wahala K et al. Inhibition of human aromatase by mammalian lignans and isoflavonoid phytoestrogens. Steroid Biochem Molec Biol, 1993. 44(2): 147-53.

11. Dixon RA. Phytoestrogens. Annual Review of Plant Biology, 2004, 55: 225-261.

12. Lissin LW, Cooke JP. Phytoestrogens and cardiovascular health J Amer. Coll. Cardiol., 2000, 35(6) 1403-1410.

13. UpmalisD.H., Lobo R., Bradley J. Vasomotor symptom relief by soy isoflavone extract tablets in postmenopausal women: a multicenter, double-blind, randomized, placebo-controlled study. Menopause, 2000, 7(4): 236-242.

14. Jeffrey A. Tice, Bruce Ettinger, Kris Ensrud et. al. Phytoestrogen supplements for the treatment of hot flashes: The isoflavone clover extract (ICE) study: a randomized controlled trial. JAMA 2003; Vol 290(2): P 207-214
15. Tully DB, Allgood VE, Cidlowski JA. Modulation of steroid receptor-mediated gene expression by vitamin B6. FASEB J, 1994, 8(3): 343-49.

16. Butterworth M, Lau SS, Monks TJ. 17 ß-esiradiol metabolism by hamster hepatic microsomes. Implications for the catechol-O-methyl transferase-mediated detoxication of catechol estrogens. Drug Metab Dispos, 1996, 24(5): 588-94.

17. Bender DA. Novel function of vitamin B6. Proceedings Nutr Soc, 1994, 53: 625-630.

18. Громова О.А., Торшин И.Ю., Лиманова О.А., Никонов А.А. Патофизиология вегетативно-сосудистых пароксизмов (приливы) у женщин в период менопаузы и механизм действия $\beta$-аланина. Новая клинико-фармакологическая концепция. Гинекология, 2010, 2: 29-36./ Gromova O.A., Torshin I.Y., Limanova O.A., Nikonov A.A. Pathophysiology of vegetative and vascular paroxysms (hot flashes) in women in postmenopausal period and mechanisms of $\beta$-alanin action. New clinical and pharmacological concept. Gynecology, 2010, 2: 29-36.

19. Jenks BH, Iwashita S, Nakagawa Y, Ragland K, Lee J, Carson WH, Ueno T, Uchiyama SA. Pilot study on the effects of S-equol compared to soy isoflavones on menopausal hot flash frequency. J Womens Health (Larchmt), 2012 Jun, 21(6): 674-82.

20. Freedman RR. Treatment of menopausal hot flashes with 5-hydroxytryptophan. Maturitas, 2010 Apr, 65(4): 383-5. 